\title{
Digital Storytelling Melalui Media Sosial dalam Aktivitas Kehumasan Pada Perguruan Tinggi Alih Status
}

\author{
Yuliani Widianingsih ${ }^{\text {a,1 }}$ dan Intan Putri Cahyani ${ }^{\text {b,2* }}$ \\ a,b Universitas Pembangunan Nusantara "Veteran" Jakarta \\ Email: 'yuliani35@yahoo.com dan²intanputri@upnvj.ac.id* \\ *corresponding author
}

\section{Keywords:}

digital storytelling, social media, engagement, analytical tools, public relations

\begin{abstract}
Transferring the status from a private university to a state university makes the Universitas Pembangunan Nasional Veteran Jakarta has more responsibility in the management and governance of communication. Therefore available social media as PR tools that can be reached by all stakeholders is significant. As an institution engaged in education, UPN Veteran Jakarta is active in using social media and has even made achievements. In PR activities of UPN Veteran Jakarta as the new state university through social media, the form of communication is carried out in the form of the use of stories or narratives combined with various elements or known as digital storytelling. Therefore, researchers are interested in researching digital storytelling through social media at UPN Veteran Jakarta as a university that is experiencing a status change. This type of research is a qualitative descriptive using the case study method. The object of research is focused on digital storytelling on the activities of all social media accounts owned by UPN Veteran Jakarta. The research data collection was carried out through (1) observation in the form of daily monitoring of the activities of all social media, (2) interviews with leaders and PR staff of UPN Veteran Jakarta. The study found that digital storytelling is a new way of building and maintaining brand reputation, spoken-content is the main key in digital storytelling, and social media makes digital storytelling more powerful and impactful.
\end{abstract}

\begin{abstract}
ABSTRAK
Alih status dari PTS menjadi PTN Baru membuat Universitas Pembangunan Nasional Veteran Jakarta memiliki tanggung jawab lebih dalam manajemen dan tata kelola komunikasi. Oleh karena itu ketersediaan media sosial sebagai PR tools yang bisa dijangkau seluruh stakeholder menjadi penting. Sebagai lembaga yang bergerak di bidang pendidikan, UPN Veteran Jakarta tergolong aktif dalam menggunakan media sosial dan bahkan telah menorehkan prestasi. Dalam aktivitas PR UPNVJ sebagai PTN Baru melalui media sosial, bentuk komunikasi yang dilakukan berupa penggunaan cerita atau narasi yang dikombinasikan dengan berbagai elemen atau dikenal dengan digital storytelling. Oleh karena itu, peneliti tertarik untuk meneliti tentang digital storytelling melalui media sosial di UPN Veteran Jakarta sebagai Perguruan Tinggi yang mengalami alih status. Tipe penelitian ini adalah deskriptif kualitatif dengan metode studi kasus. Objek penelitian difokuskan pada digital storytelling pada aktivitas seluruh akun media sosial milik UPN Veteran Jakarta. Pengumpulan data penelitian ini dilakukan melalui (1) observasi berupa pemantauan harian aktivitas semua media sosial UPNVJ, (2) wawancara dengan pimpinan dan humas UPNVJ. Hasil penelitian menunjukkan bahwa digital storytelling merupakan cara baru dalam membangun dan memelihara reputasi brand, konten yang berbicara adalah kunci utama dalam digital storytelling, dan media sosial membuat digital storytelling lebih efektif dan berdampak
\end{abstract}




\section{PENDAHULUAN}

Universitas Pembangunan Nasional Veteran Jakarta resmi berubah status menjadi Perguruan Tinggi Negeri (PTN) sejak 6 Oktober 2014 (Peraturan Presiden Republik Indonesia Nomor 120 Tahun 2014 Tentang Pendirian UPN "Veteran" Jakarta). Alih status dari PTS menjadi PTN Baru memberikan dampak sangat signifikan terhadap UPN Veteran Jakarta sebagai sebuah institusi pendidikan, terutama terkait visi misi organisasi. Sebagai Perguruan Tinggi Negeri, UPN Veteran Jakarta memiliki tanggung jawab untuk melaksanakan good governance dalam tata kelola dan manajemen. Pengelolaan informasi publik yang aktif dan responsif menjadi salah satu indikator utama (Keputusan Rektor UPN Veteran Jakarta Nomor: Kep/624.1/ UN61.0/2016 tentang Rencana Strategis Universitas Pembangunan Nasional "Veteran” Jakarta Tahun 2016-2020). Oleh karena itu ketersediaan media sosial yang bisa dijangkau seluruh stakeholder menjadi penting. Media sosial juga digunakan oleh organisasi sebagai salah satu PR tools dalam membangun reputasi, tidak terkecuali UPN Veteran Jakarta melalui humas institusi.

PTN yang memiliki positioning sebagai Kampus Bela Negara tersebut memiliki berbagai media sosial yang tergolong aktif seperti official website, Instagram, Facebook, Twitter, dan juga Youtube. Sebagai contoh, akun Instagram UPN Veteran Jakarta yaitu@upnveteranjakarta, per Januari 2020 memiliki 19.4 K pengikut dan terdapat 435 unggahan berupa foto dan video. Selain itu, Instagram UPN Veteran Jakarta tercatat aktif membagikan instastory. Sedangkan untuk channel Youtube, kampus yang memiliki semboyan Widya Mwat Yasa ini tergolong masih baru karena baru bergabung pada tanggal 5 September 2017 dan sampai Januari 2020 telah memiliki 3.5K subscriber dan 130 video yang telah dibagikan. Video yang diunggah berisi berbagai kegiatan baik akademik maupun non-akademik seperti prosesi wisuda, dies natalis, Pengenalan Kehidupan Kampus Mahasiswa Baru (PKKMB), Kuliah Umum di tingkat universitas dan fakultas, dan juga kegiatan seminar.

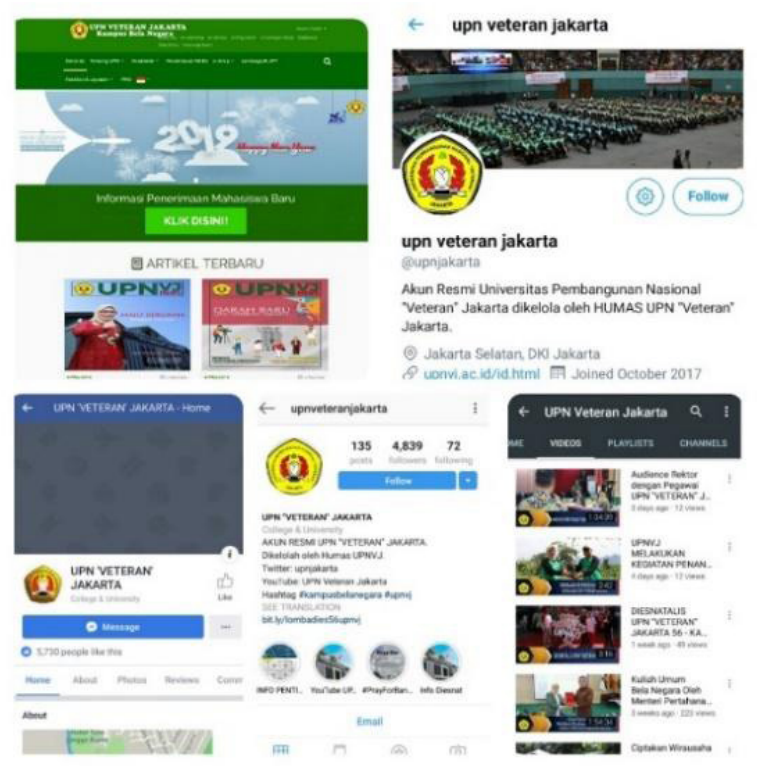

Gambar 1. Tampilan Tangkapan Layar Media Sosial UPNVJ

Selama dua tahun berturut-turut UPN Veteran Jakarta mendapatkan penghargaan dari Kementerian Riset, Teknologi, dan Pendidikan Tinggi (Kemenristekdikti) yaitu Peringkat satu dalam Kategori Website Perguruan Tinggi Negeri Baru pada Anugerah Humas PTN dan Kopertis 2017 (upnvj.ac.id, 2019). Kemudian di awal tahun 2019, UPN Veteran Jakarta kembali memenangkan penghargaan anugerah humas 2018 sebagai terbaik III katagori media sosial (upnvj.ac.id, 2019).

Sebagai PTN Baru, media sosial menjadi salah satu strategi yang digunakan Humas Universitas dalam upaya stakeholder engagement. Media Sosial, dan digital storytelling adalah hal yang saling berkaitan dalam aktivitas Public Relations, terutama di era disruptif saat ini. Dalam observasi awal yang dilakukan, peneliti menemukan berbagai bentuk komunikasi dalam bentuk cerita atau narasi yang menggunakan berbagai elemen, seperti foto, infografis, ilustrasi ataupun video yang membentuk brand story dari UPN Veteran Jakarta di berbagai media sosial.

Dalam praktik komunikasi, gaya bercerita merupakan bentuk narasi di mana suatu organisasi menghubungan filosofi dan jati diri mereka dalam membangun percakapan dengan khalayak. Sebuah cerita dapat membentuk posisi strategis pada organisasi, dengan menterjemahkan, mengintepretasikan serta menyelaraskan brand dan memastikan bahwa komunikasi dapat menguatkan cerita dan membangun brand (Baker \& Boyle, 2009). Selain itu digital storytelling dapat mengikat brand dengan nilai dan emosi yang melekat, menambah otensitas dan sense of quality serta menjelaskan 
diferensiasi organisasi tersebut jika dibandingkan dengan competitor sejenis (Kristensen, 2002). Oleh karena itu, penelitian ini bertujuan untuk menganalisis bagaimana digital storytelling dalam aktivitas media sosial UPN Veteran Jakarta sebagai Perguruan Tinggi yang mengalami peralihan status.

Storytelling adalah salah satu bentuk komunikasi yang menekankan pada cerita. Ini adalah cara mengkomunikasikan identitas atau peristiwa tertentu, di mana gambar, foto, video dan gambar sering digunakan. Sebaliknya narasi yang digunakan terdiri dari penuturan verbal dari gambar, dengan kata lain, foto itu sendiri tidak cukup untuk menceritakan sebuah cerita (Chalfen, 1987; Miller \& Edwards, 2007). Namun, dengan diperkenalkannya teknologi digital baru, narasinya telah berubah, dan kisah-kisahnya diceritakan dengan menggunakan gambar, foto, video yang dibagikan melalui multiplatform (dalam hal ini media sosial) yang dikenal dengan digital storytelling. Berbagai gambar, foto, dan video itulah yang berbicara sendiri dan mewakili puluhan, ratusan bahkan ribuan kata (Kurvinen, 2003; Makela, Giller, Tscheligi \& Sefelin, 2000).

Berangkat dari teori postmodern dan strategi pemasaran kontemporer, Raymond (2016) mengangkat penelitian dengan judul Dior And Digital storytelling: On The Marketing Of Luxury Brand Narratives. Dalam penelitian ini, digital storytelling ditekankan sebagai sarana virtual yang dengannya sebuah cerita dapat diorganisir. Melalui digital storytelling menunjukkan bahwa individu menghubungkan titik-titik cerita dengan membandingkan "bacaan" mereka dengan yang lain. Untuk mengkonseptualisasikan model ini dalam fesyen, penelitian ini mengikuti kampanye Christian Dior's Secret Garden yang menggunakan media Instagram dan YouTube. Berusaha memahami interpretasi konsumen ketika cerita ini berkembang, penelitian ini bertujuan untuk mengukur interaksi media dan audiens dalam parameter analisis jejaring sosial. Dalam temuannya, Raymond menunjukkan keberhasilan pemasaran e-word-of-mouth, dan menunjukkan kekuatan film fesyen sebagai media komunikasi ilustratif.

Selanjutnya dalam penelitian Garsbo dan Wittberger (2015) yang berjudul A Picture is Worth a Thousand Words, saat ini terjadi pergeseran dalam perilaku berkomunikasi manusia. Seiring dengan perkembangan media, kita menyesuaikan diri dengan cara baru yang memungkinkan untuk bersosialisasi satu sama lain. Pada dunia digital yang kita tinggali saat ini, semakin banyak orang terhubung melalui media sosial (LaRose, Connolly, Lee, Li \& Hales, 2014).

Situs jejaring sosial memungkinkan interaksi antar teman serta kemungkinan mendapatkan teman dan kolega baru termasuk di dunia bisnis. Ketika situs jejaring sosial baru muncul dan menjadi populer, perilaku konsumen akan berubah dan beradaptasi dengan seperangkat pedoman baru. Meskipun jejaring sosial adalah semua tentang berkomunikasi, perilaku bersosial media sangat berbeda tergantung pada media dan oleh karena itu penting untuk memahami berbagai jenis perilaku ini (LaRose, Connolly, Lee, Li \& Hales, 2014). Berdasarkan hal tersebut, perusahaan yang telah mulai berinvestasi dalam aktivitas media sosial mencoba untuk meningkatkan keterlibatan pelanggan dan mempererat komunikasi dengan mereka.

Membangun dan memelihara reputasi yang positif dan kuat menjadi tujuan utama seorang praktisi PR. Mengingat reputasi merupakan bentuk investasi jangka panjang yang muncul sebagai faktor penentu bagi keputusan publik tentang sikap dan perilakunya terhadap keberadaan organisasi/produk. Reputasi sebuah Lembaga merepresentasikan "jaringan" reaksi afektif atau emosional baik itu reaksi positif maupun negatif, kuat atau lemah dari multistakeholder terhadap lembaga (Trimanah, 2012). Oleh karena itu dibutuhkan rencana strategi yang tersusun matang dalam proses membangun reputasi berupa alternatif yang dipilih untuk direalisasikan guna mencapai tujuan PR dalam kerangka suatu rencana kehumasan.

Perencanaan PR disusun berdasarkan empat alasan, yaitu (1) menentukan target dan sasaran PR yang nantinya akan menjadi ukuran keberhasilan atas hasil yang telah tercapai, (2) memperhitungkan alokasi sumber daya yang diperlukan dari segi waktu pengerjaan, biaya yang dibutuhkan serta orang-orang yang terlibat, (3) menyusun skala prioritas sesuai dengan tujuan yang ingin dicapai dalam jangka pendek, jangka menengah dan jangka Panjang, dan (4) menerapkan prinsip USGF, yaitu Urgency, Seriousness, Growth, dan Feasibility untuk masing-masing bentuk komunikasi yang akan dilakukan dalam mencapai tujuan (Trimanah, 2012).

\section{METODOLOGI PENELITIAN}

Tipe penelitian ini adalah deskriptif kualitatif dengan metode studi kasus. Jenis penelitian ini memiliki tujuan untuk mendeskripsikan dan menarasikan berbagai fakta dan sifat populasi atau objek tertentu secara sistematis, mendalam dan akurat (Kriyantono, 2020). Riset kualitatif memiliki prosedur riset dengan menjelaskan fenomena dengan sangat mendetail dan komprehensif melalui pengumpulan data sedalam-dalamnya yang selanjutnya disebut thick description. Dengan kata lain, penelitian ini lebih fokus pada kedalaman (holistic/depth) daripada keluasan (breadth). Sedangkan studi kasus merupakan metode riset yang mengacu pada berbagai sumber data yang bisa dimanfaatkan dalam proses riset, menguraikan, dan menjelaskan secara detail dan mendalam tentang berbagai aspek individu, suatu kelompok, suatu organisasi (komunitas), suatu program, atau suatu situasi sosial. Dalam studi kasus, peneliti berupaya menganalisis sebanyak mungkin data mengenai subjek yang diteliti. Menggunakan berbagai metode seperti wawancara, pengamatan, penelaahan dokumen, hasil survei dan data apapun untuk menguraikan suatu kasus secara terperinci namun komprehensif (Kriyantono 2020). 
Robert K. Yin (2006) memberikan batasan mengenai metode studi kasus sebagai riset untuk menyelidiki dan memeriksa fenomena di dalam konteks kehidupan nyata, jika terdapat batas antara fenomena dan konteks kurang terlihat tegas, dan di mana multi sumber bukti dimanfaatkan. Menurut Mulyana (2001), studi kasus berusaha mempelajari, menerangkan, dan menginterpretasi suatu kasus dalam konteksnya yang alami tanpa intervensi pihak luar.

Pengumpulan data penelitian ini dilakukan melalui metode (1) observasi melalui social media monitoring dan (2) wawancara mendalam. Observasi ini dibutuhkan periset untuk mengamati aktivitas akun media sosial UPN Veteran Jakarta yang menggunakan digital storytelling secara eksplisit melalui beberapa akun social media analytic tools berbayar. Kedua, metode wawancara mendalam, di mana peneliti melakukan kegiatan wawancara terus-menerus untuk menggali informasi dari key informan yaitu humas Universitas guna memahami aktivitas media sosial. Data yang dikumpulkan oleh peneliti merupakan data-data langsung yang berasal dari responden melalui observasi aktivitas media sosial UPN Veteran Jakarta melalui social media analytic tools, dan wawancara mendalam terhadap subjek penelitian

Dari data yang telah dikumpulkan, proses selanjutnya adalah analisis dan interpretasi data riset kualitatif. Tahap analisis data memegang peran penting dalam riset kualitatif, yaitu seebagai faktor utama penilaian kualitas tidaknya riset. Dalam riset kualitatif, menggunakan cara berpikir induktif, yaitu cara berpikir yang berangkat dari hal-hal khusus (fakta empiris) menuju hal-hal yang umum (tataran konsep).

Proses pertama yang dilakukan pada data yang sudah terkumpul adalah dengan melakukan pengklasififikasian atau kategorisasi dengan mempertimbangkan kesahihan data dan selanjutnya dilakukan pemaknaan terhadap data. Pemaknaan ini merupakan prinsip dasar riset kualitatif, yaitu bahwa realitas ada pada pikiran manusia, realitas adalah hasil konstruksi sosial manusia. Dalam proses ini, berteori penting untuk menghindari blocking interpretation. Pada tahap ini peneliti menjelaskan pola-pola hubungan antar data atau konsep sehingga mengandung makna tertentu (proposisi) secara teoritis, termasuk juga menjelaskan secara teori rancangan model baru, atau pemetaan model. Dari hasil proposisi tersebut, termasuk di dalamnya rancangan model, teori baru, hasil pemetaan kemudian ditarik ke dalam simpulan riset (Kriyantono, 2020).

\section{HASIL DAN PEMBAHASAN}

\section{A. Digital storytelling, cara baru membangun dan memelihara Reputasi Brand}

Tren Public Relations ke depan mencakup empat hal hal, yaitu issue management, digital storytelling, social listening, dan big data. Melalui sejarah, manusia beralih ke cerita untuk menemukan makna dalam berbagai hal. Storytelling atau bercerita merupakan kebutuhan sosial manusia paling mendasar yang harus bisa dikelola oleh PR dalam proses menyampaikan pesan komunikasi kepada audiens. Hadirnya berbagai platform yang beragam di era digital memudahkan para praktisi PR untuk menjangkau audiens lebih cepat. Hal tersebut tentu sangat membantu praktisi PR untuk merancang konten storytelling. Tujuan utama PR adalah membangun dan memelihara reputasi. Storytelling dalam kaitannya dengan reputasi adalah dengan menceritakan hal-hal yang telah dilakukan perusahaan. Melalui storytelling, PR dapat memberikan informasi yang dibutuhkan publiknya, baik internal maupun eksternal (Cahyani \& Widianingsih, 2020).

Bentuk storytelling melalui media sosial yang dilakukan oleh Humas UPN Veteran Jakarta dalam setiap unggahannya berupa rilis berita kegiatan yang terlaksana di lingkungan UPNVJ, pengumuman-pengumuman kegiatan akademik maupun non-akademik. Bentuk unggahan diceritakan dalam bentuk foto, video, ataupun grafis dan setiap unggahan disertai caption singkat yang menerangkan tentang kegiatan ataupun pengumuman tersebut.

Antar Venus, Wakil Rektor Bidang Akademik menjelaskan bahwa saat ini UPN Veteran Jakarta bertransformasi dari Perguruan Swasta menjadi Perguruan Tinggi Negeri di mana prestasi menjadi sebuah budaya. Oleh karena itu, secara rutin Humas UPN Veteran Jakarta mengkomunikasikan dengan cerita tentang berbagai prestasi yang diraih oleh para civitas akademika melalui unggahan media sosial disertai tagar \#majubersamaraihprestasi. Cerita-cerita tersebut tidak lain untuk membentuk sense of belonging dan rasa bangga terhadap almamater dan membangun reputasi positif di mata publik. Selain itu, sebagai kampus yang sudah go-green, UPN Veteran Jakarta secara konsisten menyisipkan warna hijau dalam semua brandingnya di media sosial untuk menanamkan persepsi brand kepada semua publik.

Cerita yang baik adalah cerita yang dapat membangun percakapan dan meningkatkan engagement di mana cerita itu berada. Oleh karena itu, partisipasi dalam proses membentuk pengaruh sebuah brand dilihat dari berbagai aktivitas yang ada dalam percakapan yang ada di media sosial seperti komentar yang selalu ada di setiap unggahan media sosial, yang terkadang komentar tersebut mengajak orang lain untuk ikut berkomentar juga di unggahan tersebut, ataupun akun lain (influencer) yang selalu menggunakan tagar \#UPNVJ, \#kampusbelanegara ketika melakukan unggahan yang berkaitan dengan kampus UPNVJ. Oleh karena itu secara tidak langsung, UPN Veteran Jakarta telah terbantu dengan influencer dari berbagai media sosial yang digunakan, karena mereka turut melakukan digital storytelling dan membangun engagement. 


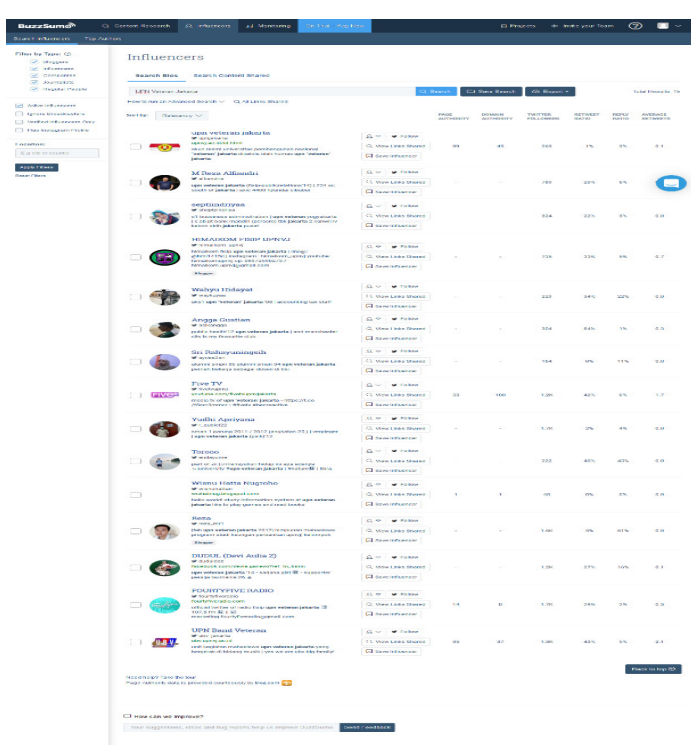

Gambar 2. Influencers Based on Analytics for Twitter Sumber: Olahan Peneliti

Sebagai sebuah produk narasi digital dan perluasan teori penceritaan, digital storytelling adalah praktik berbagi informasi dan penciptaan makna (Irwin, 2014). Dengan menghubungkan titik-titik 'cerita', individu dapat merumuskan makna mereka sendiri dan membangun interpretasi yang lebih besar dengan membandingkan 'bacaan' mereka dengan orang lain. Dari perspektif teoritis, baik produsen maupun konsumen menggunakan digital storytelling untuk merangkai pengalaman yang tidak berhubungan menjadi episode yang saling terkait dan bermakna.

Dalam tindakan social tagging atau penandaan sosial atau memposting komentar di platform tempat cerita ini disiarkan, individu dapat berpartisipasi dalam proses membentuk pengaruh sebuah brand. Karena audiens ini terlibat dalam kepentingan bersama dari perwakilan merek (Muñiz dan O'Guinn), digital storytelling juga berfungsi sebagai pintu gerbang untuk aliran komunikasi dua arah dalam parameter komunitas sebuah brand. Dibangun berdasarkan model desa global Marshall McLuhan, digital interface memungkinkan pencerita (storyteller), atau lebih tepatnya brand, untuk menyajikan fenomena ini pada front internasional yang saling terhubung (Irwin, 2014). Melalui persatuan ini, para opinion leader dan follower bermunculan. Namun, berlawanan dengan kontribusi McLuhan terhadap teori komunikasi media massa, logika dari digital storytelling mengasumsikan bahwa 'cerita' pada akhirnya dilakukan ketika pengguna berbagi dan mendiskusikan temuan mereka dengan orang lain. Hal di atas lebih condong pada untuk temuan Gruzd dan Wellman (2014) tentang perubahan dari masyarakat yang dipengaruhi secara sosial ke masyarakat yang dipengaruhi jaringan, pengguna tidak lagi terlalu terpengaruh oleh 'media massa' dan justru bergantung pada pendapat para opinion leader dalam jaringan mereka.

Pada dasarnya, storytelling mengkomunikasikan bagaimana dan mengapa kehidupan berubah (McKee, 2003:6). Sebuah cerita adalah perkembangan substansi yang ditambatkan pada suatu masalah, yang dapat mengikat penonton dengan perasaan dan pemahaman (Bryan, 2011: 13). Storytelling adalah alat yang efektif untuk digunakan, namun cerita harus dipetik secara akurat dan disesuaikan dengan kondisi. Sebagian dari tujuan yang dapat dicapai melalui storytelling adalah untuk memicu aktivitas, menyampaikan identitas, mengirimkan penghargaan, memberi energy perubahan, berbagi pembelajaran, dan memimpin individu ke masa depan (Denning, 2004: 5).

\section{B. Konten yang berbicara adalah kunci utama dalam storytelling}

Manusia pada dasarnya adalah makhluk visual. Oleh karena itu konten yang paling banyak menarik perhatian audiens adalah yang berbentuk video, foto, grafis seperti yang ada di media sosial berupa Instagram dan Youtube sehingga berdasarkan hasil analytics tools, dua akun media sosial tersebut yang paling tinggi dalam hal engagement. 

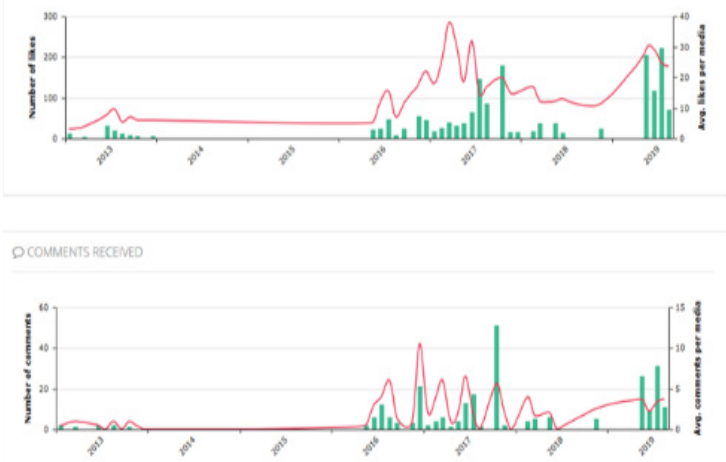

Gambar 3. Engagement Based on Analytics for Instagram (Sumber: Olahan Peneliti)

Dalam digital storytelling, Konten harus kreatif namun mudah untuk dicerna, oleh karena itu konten harus bisa menyentuh sisi emosi dari audiens. Dalam menggali ide-ide yang prospektif, PR harus merancang ide cerita yang menarik. Selain harus kreatif, ide juga dijaga agar tetap sederhana sehingga audiens dapat menangkap isi pesan komunikasi yang dimaksudkan oleh Perusahaan. Oleh karena itu peran manajemen isu dalam aktivitas PR menjadi sangat penting. Di sini konteks konten harus dijaga, cerita yang dibuat harus fokus pada pesan utama, sederhana, eksplisit dan tidak terlalu panjang. Sebisa mungkin video dibuat dengan durasi tidak lebih dari tiga hingga lima menit, foto atau grafis pun harus menonjolkan point of interest tertentu.agar audiens memperoleh insight baru setelah menonton. Caption yang dibuat pun, harus memperhatikan jumlah karakteristik, jangan terlalu minimalis tetapi jangan juga terlalu panjang serta merepresentasikan visual yang diunggah. Inti utamanya adalah menjaga perhatian audiens dan bisa membangun percakapan.

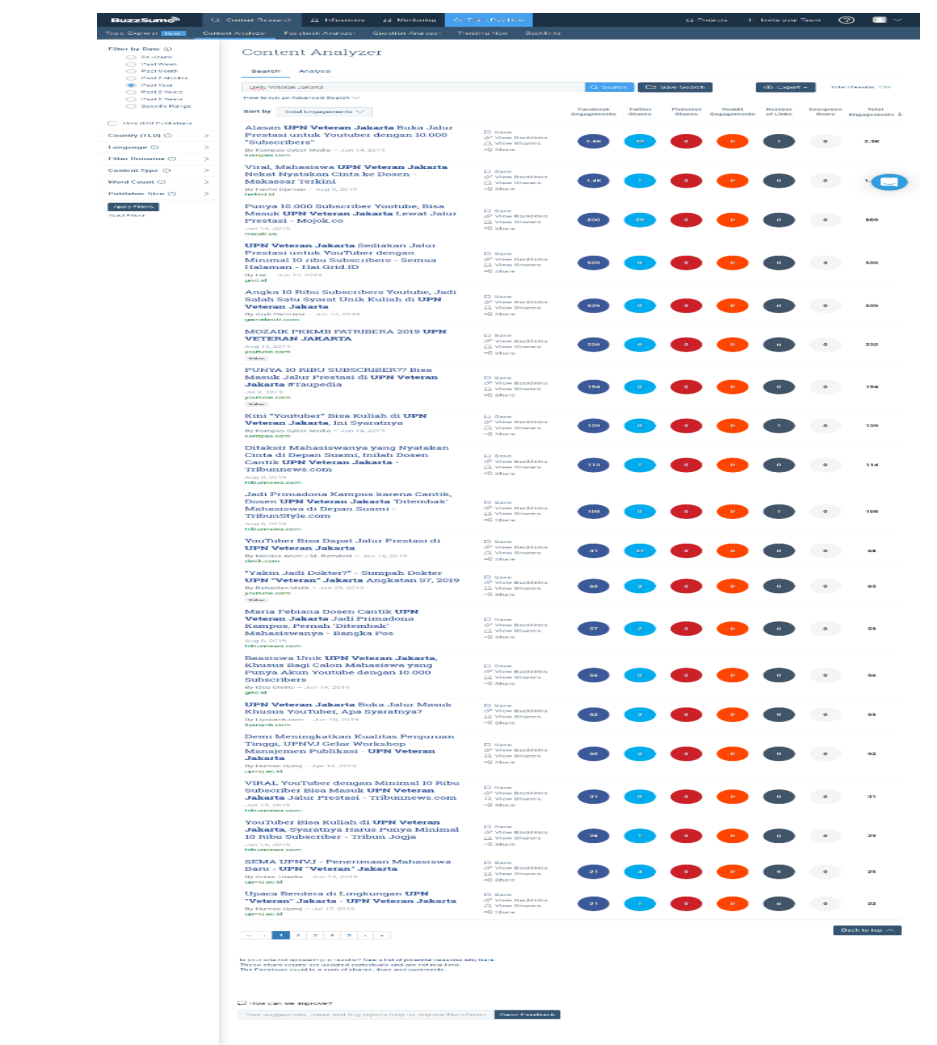

Gambar 4. Engagement Content Analyzing of UPNVJ activities on social media Sumber: Olahan Peneliti

Dari berbagai unggahan yang berkaitan dengan UPN Veteran Jakarta, konten yang paling mendapatkan engagement tertinggi selama Januari hingga September 2019 adalah konten tentang (1) UPN membuka jalur prestasi bagi Youtuber, (2) berita viral Maria Febiana Christanti, dan (3) Mozaik Patribera PKKMB 2019. 
Dalam digital storytelling, konten yang berbicara harus menjadi prioritas bukan hanya desain. Walaupun Estetika dan desain memiliki peran signifikan dalam konten, namun PR harus tetap menaruh perhatian yang besar pada isi konten yang bercerita, karena merupakan aspek yang terpenting. Selanjutnya, memilih medium yang relevan. Dalam tahapan merancang konten, penting bagi PR untuk melakukan riset audiens dan platform apa yang paling disukai oleh audiens. Hal ini penting agar konten tepat sasaran dan engagement yang terjadi bisa optimal. Oleh karena itu memahami karakteristik dan psikografis dari masing-masing target menjadi sangat penting. Story telling yang diberikan harus mementingkan konten, di mana konten harus relevan dengan target audiens, serta dapat memilih media yang sesuai.

Konten yang berbicara akan membangun sebuah interaksi, dialog atau percakapan dalam medium yang digunakan, atau dalam istilah PR kita mengenal dengan istilah engagement. Bentuk engagement yang terjadi di media sosial yaitu berupa hits dalam artikel yang diunggah di website; subscriber, views, likes, dislikes, komentar di akun Youtube; follower, likes, reply, retweet, mention, direct message di Twitter; follower, views, likes, repost, mention, direct message di Instagram. Bentuk percakapan yang dilakukan oleh follower dan influencer terkait tentang UPNVJ antara lain membicarakan hot issues yang sedang terjadi dengan memberikan pendapat pribadinya, dengan gaya bahasa serius maupun bercanda.

Tujuan yang khas membutuhkan berbagai jenis cerita. Untuk memicu suatu kegiatan, cerita harus mewakili perubahan yang efektif yang telah dilaksanakan sebelumnya namun memberikan kesempatan kepada khalayak untuk membayangkan bagaimana itu bisa berfungsi dalam keadaan mereka (Denning, 2004). Sebagai alat untuk branding, alur cerita harus menggambarkan keterikatan khalayak dengan cerita (Kristensen, 2002). Sebelumnya Aaker (2010) mengungkapkan bahwa storytelling adalah sebuah perjalanan cerita juga merupakan bagian dalam sebuah ilmu pemasaran. Beliau juga menambahkan bahwa saat ini setiap bisnis perlu mengajak customer mereka. dalam sebuah perjalanan produk atau jasa mereka. Dengan kata lain adalah turut melibatkan konsumen dalam perjalanan produk mereka.

Alasan di balik kenapa mengapa storytelling sangat penting yaitu (Aaker, 2014) (1) Cerita membentuk bagaimana orang-orang melihat kita. Penelitian menyebutkan bahwa cerita yang orang lain katakan mengenai diri kita, mempengaruhi bagaimana mereka melihat kita. Sama halnya dengan konsumen yang bercerita mengenai produk kita. (2) Cerita adalah alat yang mengandung kekuatan. Ketika kita bercerita pada seseorang, mereka akan sejenak mendengarkan, disitulah terjadi proses mendengar. Dalam konteks cerita di dunia daring, berarti kita membaca. Mendengarkan dan membaca adalah salah satu manifestasi dari kekuatan (power) dalam storytelling. (3) Cerita membujuk sekaligus menggerakkan orang untuk berperilaku tertentu. Cerita merupakan alat untuk mengadvokasi berbagai ide kita. Selain itu cerita mampu merepresentasikan perusahaan dan tujuan kita.

\section{Media Sosial Membuat Digital Storytelling Lebih Kuat dan Berdampak}

Memanfaatkan kekuatan storytelling, institusi dapat memengaruhi persepsi merek dan produknya dan menciptakan hubungan emosional dengan audiens. Berkat media sosial, digital storytelling menjadi lebih kuat dari sebelumnya, sehingga dapat dimengerti bahwa para praktisi PR memiliki pandangan yang tajam pada tren ini dengan menikmati bagaimana berbagai kisah baik dapat tumbuh, berkembang dan menginspirasi yang baru.

Saat ini UPNVJ berusaha untuk optimal dalam penggunaan semua media sosial, antara lain website, Instagram, Facebook, Twitter, dan Youtube. Folllower dan jumlah subscriber akun-akun tersebut juga meningkat secara signifikan dari waktu ke waktu.

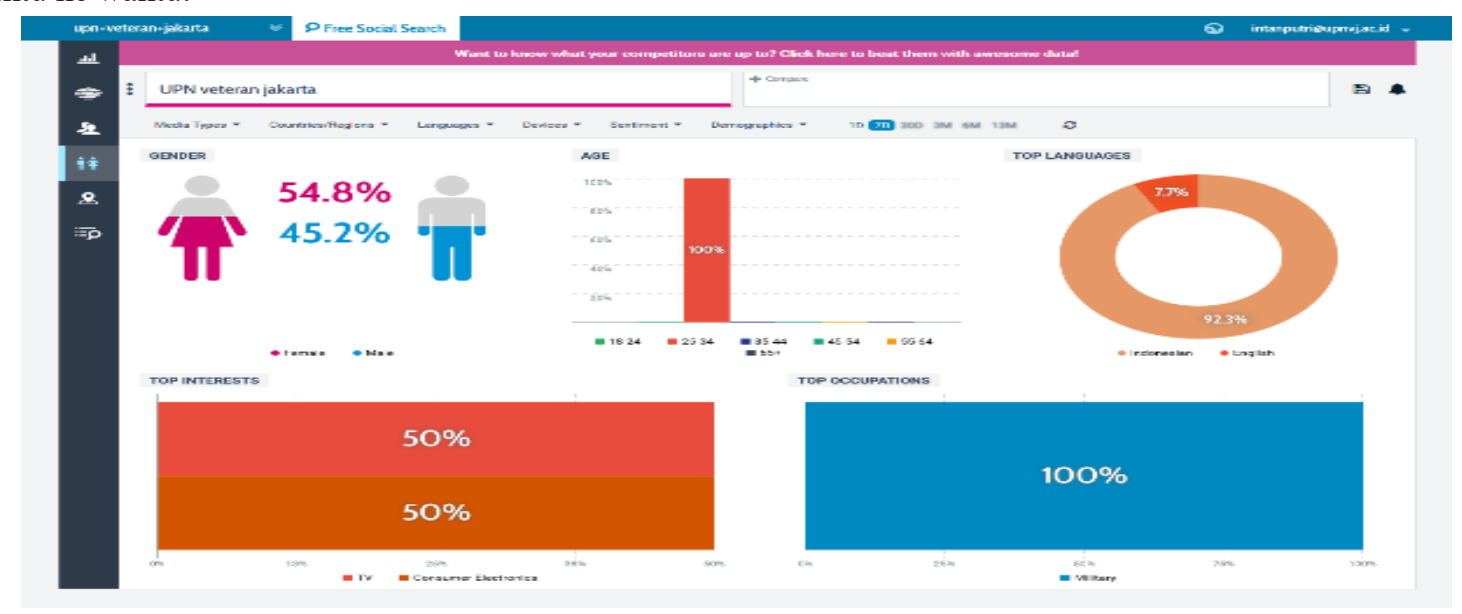

Gambar. 5 Infographic of Conversation about UPN Veteran Jakarta on social media Sumber: Olahan Peneliti

Kunci untuk storytelling adalah menciptakan hubungan emosional dengan organisasi dan merek mereka, yang jauh melampaui sekadar mendorong informasi ke hadapan audiens. Dengan media sosial, organisasi memiliki kontrol 
lebih besar untuk mengomunikasikan kisah merek mereka, sedangkan di masa lalu, satu-satunya pilihan mereka untuk menjangkau audiens adalah melalui koneksi media yang sudah ada sebelumnya. Dan saat ini digital storytelling bisa dilakukan tidak terbatas pada satu platform atau medium. Kita dapat menceritakan kisah secara digital di Instagram, Youtube, Facebook, melalui infografis, foto, atau video.

Hal yang luar biasa tentang media sosial adalah bahwa alih-alih profesional PR melakukan semua pekerjaan, justru para audiens lah yang telah membuat konten mereka sendiri. Dengan kata lain Kisah-kisah terbaik itu nyata, dan kisah-kisah yang lebih baik datang langsung dari audiens. Dan ke depan, mencoba menggabungkan cerita audiens ke dalam strategi digital storytelling menjadi keharusan bagi para Humas. Menurut Robert McKee digital storytelling adalah cara paling ampuh untuk memasukkan ide ke dunia saat ini (Lund et al., 2018)..

Storytelling adalah salah satu bentuk komunikasi yang menekankan pada cerita. Ini adalah cara mengkomunikasikan identitas atau peristiwa tertentu, di mana gambar, foto, video dan gambar sering digunakan. Sebaliknya narasi yang digunakan terdiri dari penuturan verbal dari gambar, dengan kata lain, foto itu sendiri tidak cukup untuk menceritakan sebuah cerita (Chalfen, 1987; Miller \& Edwards, 2007). Namun, dengan diperkenalkannya teknologi digital baru, narasinya telah berubah, dan kisah-kisahnya diceritakan dengan menggunakan gambar, foto, video yang dibagikan melalui multiplatform (dalam hal ini media sosial) yang dikenal dengan digital storytelling. Berbagai gambar, foto, dan video itulah yang berbicara sendiri dan mewakili puluhan, ratusan bahkan ribuan kata. (Kurvinen 2003; Makela, Giller, Tscheligi \& Sefelin, 2000).

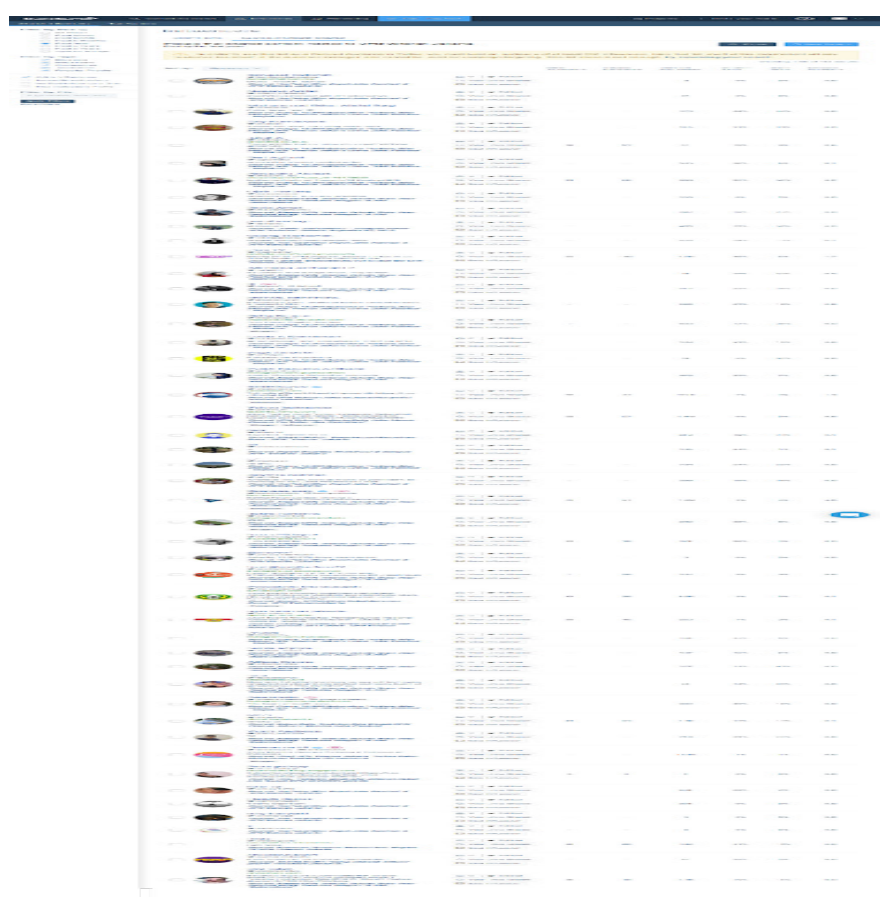

Gambar 6. People that shared content related to UPN Veteran Jakarta during the last year Sumber: Olahan Peneliti

Walaupun berdasarkan hasil analytics tools, banyak influencer telah melakukan saling berbagi konten yang berhubungan dengan UPN Veteran Jakarta, tapi ternyata belum sepenuhnya beresonansi dengan para audiens. Brand resonansi yang dihasilkan oleh unggahan di media sosial belum begitu kuat atau dengan kata lain unggahan tersebut belum bisa menimbulkan pride atau sense of belonging di kalangan civitas akademika UPNVJ. Walaupun pengelola media sosial sudah menggunakan panggilan teman-teman bela negara, namun masih dianggap belum tepat untuk membentuk identitas dan membangun kebanggaan. Oleh karena itu menjadi penting untuk menggunakan bahasa audiens serta memahami secara mendalam tentang nilai yang dianut mereka serta apa yang menjadi kebutuhan.. Dan ini menjadi tugas berat bagi Humas UPN Veteran Jakarta terutama pengelola media sosial.

Perkembangan teknologi yang begitu cepat mengakibatkan suatu era yang dinamakan sebagai era digital. Era tersebut mampu menimbulkan konvergensi antar media. Yang dimaksud dengan konvergensi media tersebut adalah penggabungan atau pengintegrasian media-media yang ada untuk digunakan dan diarahkan kedalam satu titik tujuan tertentu. Donald Ellis memberikan suatu tatanan preposisi yang mewakili sebuah sudut pandang kontemporer pada gagasan Innis dan McLuhan. Ellis menyebutkan bahwa media yang terbesar pada suatu waktu akan membentuk perilaku 
dan cara berpikir. Bagaimana cara kita mengatur informasi yang kita terima dan berhubungan dengan orang lain.

Pendekatan interaksi sosial membedakan media sosial menurut seberapa dekat media dengan model interaksi langsung (tatap muka). Media sosial adalah seperangkat aplikasi yang berjalan dalam jaringan internet dan memiliki tujuan dasar ideologi serta penggunaan teknologi web 2.0 yang dapat berfungsi untuk saling tukar menukar pesan (Kaplan \& Haenlein, 2010). Membentuk sebuah lapisan baru di mana setiap individu mengatur kehidupan mereka sendiri, yang biasa kita kenal sebagai platform. Lapisan tersebut kini mampu mempengaruhi interaksi manusia pada tingkat yang lebih tinggi, dari tingkatan tiap individu hingga antar masyarakat, bahkan pada tingkatan masyarakat yang lebih besar. Sementara itu batasan dunia online dan offline semakin memudar.

\section{KESIMPULAN}

Storytelling merupakan kebutuhan manusia paling mendasar yang harus dimanfaatkan oleh PR untuk menyampaikan pesan kepada audiens dan dengan perkembangan era digital, digital storytelling menjadi salah satu tren Public Relations kedepannya. Digital storytelling merupakan cara baru dalam membangun dan memelihara reputasi. Storytelling dalam kaitannya dengan reputasi adalah dengan menceritakan hal-hal yang telah dilakukan perusahaan. Melalui storytelling, PR dapat memberikan informasi yang dibutuhkan publiknya, baik internal maupun eksternal, dan ini telah dilakukan oleh UPN Veteran Jakarta melalui unggahan yang diceritakan dalam bentuk foto, video, ataupun grafis dan setiap unggahan disertai caption singkat di media sosial.

Selanjutnya, konten yang berbicara adalah kunci utama dalam storytelling. Dalam digital storytelling, Konten harus kreatif namun sederhana sehingga mudah diterima oleh audiens. Oleh karena itu peran manajemen isu dalam aktivitas PR menjadi sangat penting. Konten yang berbicara akan membangun engagement, di mana pada media sosial UPNVJ terlihat dari hits dalam artikel yang diunggah di website; subscriber, views, likes, dislikes, komentar di akun Youtube; follower, likes, reply, retweet, mention, direct message di Twitter; follower, views, likes, repost, mention, direct message di Instagram. Saat ini UPNVJ telah berusaha untuk optimal dalam penggunaan semua media sosial, antara lain website, Instagram, Facebook, Twitter, dan Youtube. Follower dan jumlah subscriber atau follower akun-akun tersebut juga meningkat secara signifikan dari waktu ke waktu. Hal yang luar biasa tentang media sosial adalah bahwa alih-alih profesional PR melakukan semua pekerjaan, justru para audiens lah yang telah membuat konten mereka sendiri. Dengan kata lain kisah-kisah terbaik itu nyata, dan kisah-kisah yang lebih baik datang langsung dari audiens.

\section{DAFTAR PUSTAKA}

[1] Aaker, D.A. (2010). Brand relevance: Making competitors irrelevant. San Francisco: John Wiley \& Sons. https:// doi.org/10.1002/mar.20656

[2] Aaker, D.A.(2014). Aaker on Branding: 20 Principles that Drive Success. Morgan James Publishing. https://doi.or g/10.1080/1046669X.2016.1186475

[3] Baker, B., \& Boyle, C. (2009). The timeless power of storytelling. Journal of Sponsorship, 3(1).

[4] Cahyani, I. P., \& Widianingsih, Y. (2020). Digital Storytelling dan Social Listening: Tren Aktivitas Kehumasan Perguruan Tinggi dalam Pengelolaan Media Sosial. Jurnal Ilmiah Komunikasi Makna, 8(1), 39-54. http://dx.doi. org/10.30659/jikm.v8i1.9292

[5] Denning, S. (2004). Telling tales. Harvard Business Review, 82(5), pp. 122-129.

[6] Garsbo, C \& Wittberger, ES. (2015). A Picture is Worth a Thousand Words: A qualitative analysis of how consumers identify themselves on Instagram. Thesis.Lund University.

[7] Gruzd, A., \& Wellman, B. (2014). Networked influence in social media: Introduction to the special issue. American Behavioral Scientist 58.10 (2014): 1251-9. https://doi.org/10.1177/0002764214527087

[8] UPNVJ. (2018). Humas UPN “Veteran” Jakarta Raih Juara 1 dalam Anugerah Humas PTNB. https://upnvj.ac.id/id/ berita/2018/01/humas-upn-veteran-jakarta-raih-juara-1-dalam-anugerah-humas-ptnb.html diakses 6 Januari 2019

[9] _. (2019). UPN "Veteran" Jakarta Sabet Lagi Penghargaan Anugerah Humas 2018. https://upnvj. ac.id/id/berita/2019/01/upn-veteran-jakarta-sabet-lagi-penghargaan-anugerah-humas-2018.html_diakses 6 Januari 2019

[10] Irwin, S. O. (2014). Embodied being: Examining tool use in digital storytelling. Tamara: Journal for Critical Organization Inquiry, 12(2).

[11] Kaplan, Andres \& Michael HaenLein, 2010. User Of The World, Unite! The Challenges and Opportunities Of Social Media. Business Horizons.

[12] Kristensen, H. (2002, September 26). Storytelling for virksomheder. www.ifk.dk : http://iff.dk/scripts/artikel. asp?id=711\&1ng=1

[13] Kriyantono, Rachmat. (2020). Teknik Praktis Riset Komunikasi. Jakarta: Kencana Prenada Media Group 
[14] LaRose, R., Connolly, R., Lee, H., Li, K., \& Hales, K. D. (2014). Connection overload? A cross-cultural study of the consequences of social media connection. Information Systems Management, 31(1), pp. 59-73. https://doi.org/ 10.1080/10580530.2014.854097

[15] Lund, N. F., Cohen, S.A., \& Scarles, C. (2018). The power of social media storytelling in destination branding. Journal of Destination Marketing and Management, 8(June), pp. 271-280. https://doi.org/10.1016/j.jdmm.2017.05.003

[16] Raymond, Emily. (2016). Dior and Digital Storytelling: On The Marketing of Luxury Brand Narratives. Thesis Acadia University. Ontario, Canada. https://digital.library.ryerson.ca/islandora/object/RULA\%3A5523

[17] Trimanah. (2012). Reputasi Dalam Kerangka Kerja Public Relation. Jurnal Ilmiah Komunikasi Makna, 3(1), 92102. https://doi.org/10.30659/JIKM.3.1.92-102

[18] Vannini, April. "Stories and Storytelling." Encyclopedia of Communication Theory. Thousand Oaks, Ca: Sage (2012): 935-937. Web. 3 May 2015.

[19] Yin, R. K. (2006). Studi kasus: desain dan metode. Raja Grafindo Persada. Jakarta.

[20] Keputusan Rektor UPN Veteran Jakarta Nomor : Kep/624.1/ UN61.0/2016 tentang Rencana Strategis Universitas Pembangunan Nasional "Veteran” Jakarta Tahun 2016-2020

[21] Peraturan Presiden Republik Indonesia Nomor 120 Tahun 2014 Tentang Pendirian UPN "Veteran" Jakarta (Lembaran Negara Republik Indonesia Tahun 2014 Nomor 249). 